\title{
Delivery Procedure
}

National Cancer Institute

\section{Source}

National Cancer Institute. Delivery Procedure. NCI Thesaurus. Code C81179.

Description of the method by which a fetus is delivered. 